LICENÇA CC BY:

Artigo distribuído sob os termos

Creative Commons, permite uso e distribuição irrestrita em qualquer meio desde que o autor credite a fonte original.

\title{
"AQUI É O LUGAR QUE A GENTE VIVE!"1 AS BRINCADEIRAS DAS CRIANÇAS DE UM QUILOMBO CATARINENSE
}

"THIS IS WHERE WE LIVE!" CHILDREN'S PLAY AT A QUILOMBO COMMUNITY IN SANTA CATARINA

"AQUÍ ES EL LUGAR QUE LA GENTE VIVE" LOS JUEGOS DE LOS NIÑOS DE UN QUILOMBO DE SANTA CATARINA

Elaine de Paula ${ }^{1}$

${ }^{1}$ Doutora em Educação pela UFSC. Assessora Pedagógica da Diretoria de Educação Infantil da Secretaria Municipal de Educação de Florianópolis, Florianópolis, SC, Brasil.

Resumo: Este texto contempla reflexões sobre as incursões que fiz em dois quilombos catarinenses como parte de minha pesquisa de doutorado em educação. A motivação central foi a de compreender e analisar, por meio de um estudo etnográfico, o lugar que as crianças quilombolas ocupam, como são suas práticas e experiências, e o que elas 'expressam' sobre as relações educativas que se estabelecem no espaço institucionalizado da educação infantil e no espaço da comunidade quilombola onde moram. A perspectiva teórica direcionou-se para uma interlocução entre os campos da Pedagogia, Sociologia da Infância e Antropologia. Embora a pesquisa ter se dado também na educação infantil, abarco, todavia, neste texto observações a partir dos lugares e dos tempos ocupados pelas crianças nos quilombos, em especial aludindo a seus diferentes jeitos de ser, de se expressar nos momentos de brincar. A pesquisa evidencia um alto grau de cumplicidade, autonomia e criação de brincadeiras entre as crianças nos quilombos e demostra que suas formas de expressão ou de sociabilidade podem suscitar outras maneiras de pensar a educação institucionalizada.

Palavras-chave: Criança Quilombola; Quilombo; Lugar; Brincadeira.

Abstract: This paper reflects on the incursions I made in two "quilombos" (communities originally established by escaped Afro-Brazilian slaves) in the Brazilian state of Santa Catarina as part of my doctoral research in education. The main motivation was to understand and analyze, through an ethnographic study, the place that children of the quilombos occupy, their practices and experiences, and what they express about the educational relations that are established in the institutionalized space of childhood education, and in the space of the quilombo community where they live. The theoretical perspective focused on a dialogue between the fields of Pedagogy, Sociology of Childhood and Anthropology. Although research was also conducted on early childhood education, I nevertheless include in this text observations based on the places and times occupied by children in the quilombos, mentioning, in particular, their different ways of being, and of expressing themselves in moments of play. The research shows a high degree of complicity, autonomy and creativity to play among children in the quilombos, and demonstrates that their forms of expression or sociability can give rise to other ways of thinking about institutionalized education. 
Keywords: Quilombola Child; Quilombo; Place; Play.

Resumen: Este texto abarca reflexiones sobre las incursiones que he hecho en dos quilombos catarinenses como parte de mi investigación doctoral en educación. La principal motivación fue la de comprender y analizar, por medio de un estudio etnográfico, el lugar que los niños quilombolas ocupan, como son sus prácticas y experiencias, y lo que ellas 'expresan' sobre las relaciones educativas que se establecen en el espacio institucionalizado de la educación infantil y en el espacio de la comunidad quilombola donde viven. La perspectiva teórica se ha encauzado hacia una interlocución entre los campos de la Pedagogía, Sociología de la Infancia y Antropología. Aunque la pesquisa se haya dado también en la educación infantil, abarco, también, en este texto observaciones a partir de los lugares y tiempos ocupados por los niños en los quilombos, en especial aludiendo a sus diferentes maneras de ser, de expresarse en los momentos de jugar. La investigación pone de relieve un alto grado de complicidad, autonomía y creación de juegos entre los niños en los quilombos y demuestra que sus formas de expresión o de sociabilidad pueden provocar otras maneras de pensar la educación institucionalizada.

Palabras clave: Niño Quilombola; Quilombo; Lugar; Juego.

\section{Introdução}

Trato aqui de reflexões realizadas por ocasião da minha pesquisa empírica, parte do doutoramento em Educação pela Universidade Federal de Santa Catarina, defendida em 2014. A pesquisa ${ }^{2}$ tinha por foco compreender as relações educativas entre crianças e entre crianças e adultos. O trabalho de campo foi realizado em dois quilombos e em duas salas de educação infantil da rede pública municipal da cidade de Garopaba, Santa Catarina. Para tanto, foi selecionado um grupo de sete crianças quilombolas (três meninas e quatro meninos) com idades entre quatro e seis anos. Da parte da educação infantil participou ainda um grupo de vinte crianças não moradoras das comunidades quilombolas. Dada a amplitude do propósito, no presente texto me limitarei a algumas considerações sobre as comunidades quilombolas, em especial sobre o 'lugar' destinado às crianças e seus jeitos de ser, viver e brincar. Omitirei, neste momento, referências à pesquisa junto às crianças na educação infantil.

\section{Breve perspectiva conceitual sobre quilombo}

Antes de falar especificamente sobre as crianças nos quilombos ${ }^{3}$, em particular dos do estado, lócus da pesquisa, entendo ser necessário conceituar o termo ${ }^{4}$, entendendo-o como comunidades remanescentes de quilombo.

Segundo o historiador Clóvis Moura:

Quilombo era, segundo definição do rei de Portugal, em reposta à consulta do Conselho Ultramarino, datada de 2 de dezembro de 1740, 'toda habitação de negros fugidos que passem de cinco, em parte despovoada, ainda que não tenham ranchos levantados nem se achem pilões neles'. Dessa forma, no Brasil, como em outras partes 
da América onde existiu o escravismo moderno, esses ajuntamentos proliferaram como sinal de protesto do negro escravo às condições desumanas e alienadas a que estavam sujeitos (MOURA, 1993, p. 11).

De acordo com o mesmo autor, o quilombo, no Brasil, marca sua presença durante todo o período escravista e em praticamente todo o território nacional. Depreendi disso que, enquanto existiu escravidão, também houve revolta de parte do negro escravizado. Os quilombos representaram uma das formas de protesto e de resistência às condições desumanas a eles impostas.

Embora a origem do termo "quilombo" remonte ao Brasil Colônia, e sua existência concreta nasça com os primeiros focos de resistência dos negros africanos e seus descendentes, o desconhecimento da existência desse tipo de refúgio por mais de quatro séculos na sociedade brasileira não é de todo irreal. A utilização do termo é muito recente, principalmente com a organização dos movimentos negros. Desde então, os quilombos passam a ter visibilidade com suas reivindicações e alcançam uma dimensão política. A consequência foi conseguir sua 'inclusão' na Constituição Federal.

Segundo Eliane O'Dwyer:

[...] a partir da Constituição Brasileira de 1988, o quilombo adquire uma significação atualizada, ao ser inscrito no artigo $68^{\circ}$ do Ato das Disposições Constitucionais Transitórias (ADCT) para conferir direitos territoriais aos remanescentes da comunidade de quilombos que estejam ocupando suas terras, sendo-Ihes garantida a titulação definitiva pelo Estado brasileiro (2002, p. 1, grifo do autor).

Ainda de acordo com a mesma antropóloga, comunidades quilombolas consistem em grupos que desenvolveram práticas cotidianas de resistência na manutenção e na reprodução de seus característicos modos de vida e na consolidação de um território próprio (O'DWYER,2002, p. 10-11).

Por último, falar de quilombos e quilombolas no cenário político atual, segundo Ilka Boaventura Leite, é "falar de uma luta política e, consequentemente, uma reflexão científica em processo de construção" (LEITE, 2008, p. 333).

Esse processo de construção exige também a ressignificação do termo e do próprio quilombo na atualidade. Embora o termo sobreviva no imaginário coletivo como organização homogênea, isolada e só identificada por instâncias externas, há que se rever tais premissas. De fato, admitir uma comunidade quilombola e sua identidade social significa dar ao termo o sentido de "[...] grupos que se auto-reconhecem a partir de noções de pertenças construídas e legitimadas no interior dos próprios grupos [...]" (LEITE, 2008, p. 91).

\section{Afinal, quem são as crianças quilombolas?}

Ao viver numa sociedade desigual, como a brasileira, de condições de extrema pobreza ${ }^{5}$ para a maioria da população, não é difícil perceber que as crianças são, em 
alguma medida, afetadas por essa condição. Segundo Sônia Kramer (2003, p. 84), "hoje, vivemos o paradoxo de ter um conhecimento teórico avançado sobre a infância, enquanto assistimos com horror à incapacidade da nossa geração de lidar com as populações infantis".

São diferentes campos de conhecimento, tais como os de Psicologia, Sociologia, Pedagogia, Antropologia, História, dentre outros, que produzem conhecimentos sobre as crianças. Por outro lado, há autores, como Regina Leite, que advertem:

"[...] vivemos num momento histórico e numa sociedade em que a infância vem sendo mais e mais encurtada, seja pela mídia, seja pela miséria e pela contravenção. Meninas de menos de dez anos se vestem, se pintam, se calçam se portam como mulheres adultas e sedutoras" (LEITE, 2002, p. 9).

A pergunta que naturalmente ocorre é sobre o significado de ser criança em 'diferentes' contextos sociais e culturais. As crianças quilombolas, por exemplo, 'enquadram-se' no que foi descrito? Ou simplesmente inexistem para as estatísticas e os organismos internacionais?

É necessário apontar as contradições de nossa sociedade. Se, por um lado, 'reconhece' a necessidade de realizar estudos sobre a infância e se vale de diferentes áreas de conhecimento para dialogar com a heterogeneidade constituinte das infâncias - classe social, gênero, raça e etnia -, por outro e paradoxalmente, Ihes aplica um agravo de exclusão. Refiro-me às crianças moradoras dos quilombos.

Se a infância luta por se afirmar e sair da invisibilidade a que foi relegada, há, entretanto, corpos de crianças mais invisibilizados e inferiorizados, vítimas de preconceitos históricos. As lutas para superar inferiorizações preconceituosas contra sua classe, seu gênero, sua etnia e sua raça são bem mais complexas (ARROYO; SILVA, 2012, p. 13).

Não nos resta dúvida que a vida das crianças quilombolas está atrelada à vida dos adultos, e estes, por sua vez, estão submetidos a condições de exploração econômica, social e política que marca a história da sociedade brasileira, afetando-as. Todavia, essas mesmas crianças criam brechas e oásis de liberdade, para romper, de alguma forma e ao menos em alguns momentos, com as amarras impingidas por essa estrutura. As crianças agem no cotidiano e subvertem a realidade!

As crianças quilombolas resistem e, mesmo com uma autonomia relativa, vivem suas infâncias como crianças nos contextos em que se inserem. Mas quem são elas? Como vivem? Afirmo que essas crianças não vivem a dupla alienação da infância lembrada por Ana Lúcia Goulart de Faria: "[...] a criança rica, privatizada, alienada, antecipando a vida adulta através de inúmeras atividades; e a criança pobre, explorada, também antecipando a vida adulta no trabalho" [...] (FARIA, 2003, p. 72).

As infâncias quilombolas não vivem atadas a um computador, porque esses aparelhos nem sempre existem em suas casas; não estão fixadas à televisão, porque há vida no quilombo; não Ihes é exigida uma série de atividades como natação, balé ou inglês, porque têm um compromisso com elas mesmas, que é o de crescer sem deixar 
de ser criança; não são exploradas no trabalho, porque, nos quilombos, os adultos são os únicos responsáveis por sua proteção e pela provisão.

Recorro novamente a Faria para adequar suas palavras aos quilombos em que vivem as crianças. "Um lugar [...] onde se descobre o mundo através do brincar, das relações mais variadas com o ambiente, com os objetos e as pessoas [...]. Assim, ao invés de falarmos no desaparecimento da infância [...] podemos falar em uma nova descoberta da infância" (2003, p. 72).

Ser criança quilombola não significa viver a infância apenas como uma fase cronológica da vida ou enquadrada numa ordem jurídica estabelecida. As crianças garantem seus direitos no cotidiano, em formas de expressão que marcam seu "corpo lúdico" e seu pertencimento ao quilombo: "[...] corpo lúdico ou corpo brincante, isto é, aquele que, de forma revolucionária e emancipatória, se expressa no tempo-espaço [...] (SILVA, 2012, p. 231). As infâncias assim caracterizadas superam isto ou aquilo; constroem suas experiências com base naquilo que elas descobrem, imaginam e inventam em seu dia a dia ${ }^{6}$.

As crianças do quilombo nem sempre possuem carrinhos de controle remoto, tampouco bonecas que falam, mas têm árvores, morros e lagos para brincar. Elas criam enredos, criam cenas e dão seu próprio desfecho a histórias das quais elas são autoras e atrizes. Portanto, falo aqui de crianças que ainda brincam...que brincam na 'rua', que brincam sem ter que prestar contas, que brincam, brigam, choram, ficam de mal, fazem as pazes e começam tudo de novo... a cada dia e de acordo com seus mundos e, portanto, pela perspectiva da infância e não do mundo adulto. Logo, as crianças "[...] mostram que com seus imaginários é possível construir história, cultura e arte" (SILVA, 2012, p. 216).

No quilombo, as crianças mantêm uma grande rede de relações, vivenciando aprendizagens e socializações em diferentes momentos e lugares, com adultos, adolescentes e, especialmente, com seus pares. Estão em diferentes espaços: na cachoeira, no riacho, no lago, no campo de futebol ou no parque. Participam, mesmo sem serem convidadas, da colheita de bananas, da retirada de hortaliças, da ordenha, da alimentação aos porcos, do culto religioso, da fabricação de doces, pães e bolachas. Enfim, circulam, interagem, se socializam e aprendem, mesmo quando o 'outro' não tem a intenção de ensinar. As danças também marcam esse grupo, seja na capoeira, nas rodas de samba, no Maculelê7. Seus corpos não representam um "território de disputa" (SILVA, 2012), pois, em muitos momentos, elas é que estão no controle dos seus movimentos.

A coletividade, a interatividade, a participação e as experiências construídas, partilhadas e vividas, especialmente entre pares, são aspectos específicos dessas crianças. 


\section{E por que ir ao encontro das crianças nos quilombos?}

Procuro levantar, no presente texto, aspectos do cotidiano das crianças nas comunidades quilombolas investigadas por nos permitirem conhecer seus jeitos de ser, saber, experienciar e brincar. São aspectos que ampliam nossa compreensão em torno da relação entre educação e cultura e que nos levam a perceber que as relações educativas extrapolam o espaço institucional da educação formal.

Para contribuir com o propósito de tornar as crianças parceiras no processo de construção de sua educação, procurei aproximar-me da realidade de suas vidas. Acredito que, assim, agregando existência, experiência, aprendizagem e reflexão, seja possível ir além do mero esforço de reprodução das estruturas vigentes. O objetivo central da pesquisa de doutorado convergiu nesta direção, pois, com ela, propus-me a compreender o lugar das crianças em contextos quilombolas.

Do ponto de vista que defendo, uma pesquisa que busque desvelar o lugar que as crianças ocupam, e compreender seus jeitos de se expressar exige, como princípio básico, partir dos próprios pontos de vista das crianças. É partir dos seus modos de pensar, falar, agir, enfim, de significar seus mundos sociais. Para tanto, acredito que nos deva ser permitido "invadir" seus universos e partilhar suas experiências; partilhar nossa exclusividade do adulto que fala, escreve e põe um ponto final na história. As crianças, provavelmente, têm outras "finalidades" para suas narrativas e performances. Por isso, olhá-las e escutá-las, principalmente em contextos tão pouco conhecidos e valorizados como os contextos quilombolas, poderão ampliar nossa percepção sobre o mundo. Para sonhar, sem o que não se constroem as mudanças, é imprescindível ampliar nossa percepção sobre a diversidade humana. Precisamos ser levados a enxergar aquilo que é banalizado e sobre ele indagar, justamente porque não sabemos mais encantar o nosso olhar como as crianças o fazem.

Entendo, por fim, que, quanto menores as crianças e quanto mais tempo vivam em comunidades longínquas, mais as desconhecemos e, portanto, mais desconsideradas são elas nos aspectos referentes às suas especificidades e capacidades de dizer de si mesmas nos processos sociais que as determinam, pois são consideradas não competentes para interferir ou para decidir sobre alguma coisa que diga respeito à sua própria vida. Andar na contramão de práticas sociais que as impõem ao silêncio deveria ser premissa de todo projeto educativo!

\section{Tempos e lugares do brincar construídos pelas crianças}

As crianças são informantes capazes de falar do lugar em que vivem. Além de um sentimento de pertencimento afetivo ao lugar (sentimento marcado pela fixação ao 
território do grupo social e étnico a que pertencem), elas também parecem compreender as fronteiras físicas e simbólicas entre o quilombo e as demais comunidades do entorno. Elas produzem uma territorialidade que se mantém como espaço geográfico, e por ela são produzidas, embora em permanente mudança em face dos movimentos de seus cotidianos. O lugar é vivido nas inter-relações que estabelecem com seus pares e com os adultos.

Marc Auge conceitua 'lugar' como um espaço possuidor de aspectos identitários, históricos e relacionais. Por outro lado, o autor denomina de 'não lugares' os espaços que acompanham uma supermodernidade e se caracterizam pela velocidade de tempo e consumo, citando como exemplos os supermercados, as autoestradas, os aeroportos, os centros comerciais (AUGE, 1994).

Podemos afirmar, então, que o espaço que as crianças ocupam nos quilombos é um 'lugar', pois não é apenas um lugar de passagem, mas de permanência. As crianças estão em todas as partes da comunidade (parque, horta, morros, gramado, lago, pasto, campo, sala multiuso, diferentes casas, dentre outros lugares). Elas próprias definem o parque e o gramado como lugares de encontro, de criação e de diferentes brincadeiras.

Antes de prosseguir, apresento o conceito de brincadeira, por ter sido o meio, enquanto lá estive, pelo qual as crianças se expressavam em muitos momentos. Brincadeira é uma categoria que aos poucos foi se delineando em minhas análises empíricas. Por ser uma prática social, é ao mesmo tempo uma ação cultural, assim como é sociocultural a constituição do ser humano. Concordo, pois, com o professor francês Gilles Brougère (2002, p. 20), segundo o qual "[...] o brincar não é uma dinâmica interna do indivíduo, mas uma atividade dotada de uma significação social concisa que, como outras, necessita de aprendizagem". E as crianças têm muito a ensinar; basta alguém ter interesse em aprender.

Nos dois quilombos em que realizei minha pesquisa havia lugares todo dia ocupados por brincadeiras inventadas. Percebi nas crianças autonomia, segurança e processos de identificação para reconstruir sistemas simbolizados ${ }^{8}$ e, consequentemente, reconstruir um 'modelo próprio' de cultura infantil quilombola9.

Ouso, assim, afirmar que as crianças produzem cultura à medida que conseguem algum grau de autonomia em relação à cultura que detém a hegemonia nos espaços em que elas se inserem, especialmente quando falamos em espaço escolarizado. Compartilho com alguns autores, como Corsaro (2002), a tese da 'reprodução interpretativa'. Tenho convicção de que as crianças são muito mais do que meros espectadores ou imitadores dos adultos. Imitam, sim, mas introduzem, em sua leitura de mundo, um modo próprio de compreensão das relações que estabelecem com os outros seres humanos, adultos e crianças, bem como das relações com a natureza e o lugar onde vivem.

As evidências empíricas dessa convicção estão em sua ação criativa em diferentes momentos no quilombo. Assim é que entendo uma cultural infantil constituída por crianças nos quilombos: uma forma distinta de grupo geracional, seja em relação aos 
demais grupos etários, seja em relação a outros grupos sociais. As crianças constroem um lugar com suas formas e jeitos de pensar, de fazer, de se relacionar, enfim, com seu modo de interpretar e significar a realidade, ou seja, de produzir cultura, uma cultura infantil. Distinguem-se, assim, de outros grupos infantis, ainda que guardem traços semelhantes por serem crianças. Concordo, também, com a análise de Sarmento e Pinto, quando afirmam que a interpretação das culturas infantis "não pode ser realizada no vazio social, e necessita de se sustentar na análise das condições sociais em que as crianças vivem, interagem e dão sentido ao que fazem" (PINTO; SARMENTO, 1997, p. 22).

Olhar as crianças pela ótica da diversidade, pela perspectiva de construção do lugar em que vivem é reconhecer sua alteridade em relação aos adultos, mas também em relação a grupos sociais de crianças que vivem em outros espaços, sejam estes culturais, sociais ou geográficos. Ao falar em alteridade, por exemplo, falo da criança como 'outro', como possuidora das singularidades de que se constitui e que, portanto, a distinguem. Segundo Jorge Larrosa, "a alteridade da infância é algo muito mais radical: nada mais, nada menos do que sua absoluta heterogeneidade no que diz respeito a nós e ao nosso mundo, sua absoluta diferença" (LARROSA, 1998, p. 70). Isto posto, volta a pergunta: o que as crianças falam e fazem no quilombo, do que brincam e o que as torna diferentes frente às diferenças dos 'outros' a que anteriormente me referi?

Cantar, dançar, tocar, subverter fronteiras geracionais, reconstruir um mundo microssocial no interior de uma esfera macrossocial, estar em toda parte, participar de todas as atividades cotidianas sem que isso represente um produto final, apontar as fronteiras geográficas, sociais e culturais que as distinguem dos demais grupos sociais, em especial os da escola, fortalecer cotidianamente seu pertencimento de sangue e de afeto a um grupo, enfim, imaginar e criar novas brincadeiras, são alguns dos elementos presentes na cultura infantil desse grupo!

O lugar em que elas vivem parece representar, de fato, um oásis de autonomia, de liberdade e de imaginação. Quando falo em autonomia das crianças no quilombo, não me refiro a uma total independência, mas à possibilidade de opinar, de escolher, enfim, de se inserir nos diferentes espaços e tempos da comunidade, conduzindo seus próprios interesses e atividades, combinando entre pares suas regras, tempos e espaços para a realização de brincadeiras. Quando falo em liberdade, compreendo que ela também está dentro de um limite. Quando cito a imaginação, não me refiro àquela estimulada por um acervo de produtos industrializados que, tal como um pacote para pronta entrega e pronto para ser consumido, chega diariamente aos lares, às escolas, aos parques de diversão, enfim, aos lugares onde as crianças estiverem, pela divulgação midiática, cuja influência quase devastadora age não só sobre as crianças, mas também sobre os adultos, impelindo-os a um alienante consumo. Refiro-me, isso sim, à possibilidade que as crianças têm de reorganizar experiências em seu cotidiano. O lugar vivido por elas e a relação entre elas estabelecida, nas ocasiões em que com elas estive, Ihes possibilitava descobrir conteúdos para dar vida à sua imaginação. 
Afirmo isso porque as vi, muitas vezes, traçando e definindo caminhos. Assim: acordavam cedo, saíam para a 'rua' para encontrar seus pares, subiam e desciam o morro com agilidade, falavam com desenvoltura com todos os moradores que encontravam pela frente, transmitiam recados dos adultos, entravam em diferentes casas e delas saíam, pulavam pedras, subiam em árvores, enxotavam o gado, oh,oh,oh, brincavam com os cachorros, organizavam jogos, inventavam brincadeiras com objetos da natureza, (res)significavam histórias tradicionais, criavam novos desfechos para o final, iam para a escola, voltavam da escola e, instantes depois, estavam novamente entre pares. À noite, continuavam brincando, até que... ufa! Parece que o cansaço as vencia, temporariamente. Inacreditável, o dia dessas crianças também parecia ter um "fim".

Embora as crianças parecessem pequenas diante da "imensidão" do quilombo, isso não passava de ilusão. A mobilidade que elas apresentavam, aliada ao conhecimento de tudo e de todos os que as rodeavam, conferia-Ihes um "empoderamento" que fazia com que aquele lugar lhes coubesse na palma das mãos.

A essência daquele cotidiano, que extrapolava a determinação de um espaço geográfico, era simplesmente construída pelas crianças, também por seus jeitos de ser e de fazer, o que conferia uma concretude, ao mesmo tempo singular e diversa, ao lugar por elas produzido e vivido.

Para tentar apreender um pouco desse movimento, cito algumas brincadeiras por elas inventadas. Um dos momentos que considero de reinvenção e de autonomia foi o de Zulu $^{10}$, quando resolveu fazer um arco e flecha. Ele pegou uma faca de cozinha e passou a cortar um galho que havia encontrado pelo caminho. Inicialmente, minha reação foi, obviamente, de achar que ele poderia se machucar, se cortar; depois, fiquei impressionada com sua destreza ao manusear aquela faca. Os adultos que passavam perto dele, tia e mãe, não lhe chamaram a atenção nem o aconselharam a tomar cuidado, o que pareceu demonstrar que ele utilizava aquela faca frequentemente. Após terminar o que ele intencionava fazer, guardou a faca e foi partilhar sua brincadeira com Eno no parque.

Mais uma vez, as crianças não pediram auxílio aos adultos. Já no parque, combinaram regras para utilizar o arco e a flecha, criação de Zulu. Uma delas era não atirar a flecha contra as pessoas. Elas me convidaram para brincar também e Zulu sugeriu novas regras. Cada um poderia jogar a lança duas vezes. Depois, começaram a inventar lançamentos diferentes; no entanto, um não poderia imitar o outro, regra frisada constantemente por Zulu.

Depois da brincadeira com arco e flecha, Eno falou: "Ah, vamos brincar de outra coisa?" Zulu propôs uma brincadeira de máquina. A "máquina" eram três pedaços de bambu enterrados no chão que serviriam de marchas. Eno topou a brincadeira. Ambos, Zulu e Eno, começaram a fazer o barulho da máquina ao manusearem os bambus, ou seja, "as marchas da máquina", "bruuuuummmmm".

Além das brincadeiras, podemos inferir que o profundo conhecimento a respeito da comunidade à qual pertencem lhes assegura a reinvenção desse dia a dia, tornando-o 
diferente, e singular apenas a elas. As crianças estão sempre em grupos e suas brincadeiras, embora tenham regras criadas no início de cada uma, como naquelas já citadas, ou em outras, tais como bola de gude, futebol, arco e flecha, pescaria, cata-vento, árvores de máquinas, tiro ao alvo, não são realizadas visando à competição, à seleção ou à exclusão de qualquer um dos integrantes da brincadeira. Pelo contrário, esta chegava ao fim toda vez que um dos componentes desistia de brincar..., mas logo o grupo voltava a se reunir e novas inspirações surgiam.

As crianças, além de não pedirem auxílio aos adultos, em determinados momentos elas é que os ensinam, como nas duas brincadeiras descritas a seguir.

\begin{abstract}
Zulu entra na casa onde eu estou, vê um pião sobre a mesa e me pergunta se eu sei brincar. Digo a ele que não me lembro muito de como se brinca e devolvo a pergunta a ele. Ao que ele responde rapidamente: 'Ah, eu sei brincar de pião, mas a Alice sabe mais, ela tem até um na casa dela'. (Alice ainda não estava conosco nesse momento). Zulu pega o pião da minha mão, mexe a cabeça negativamente e diz: 'oh, qué vê como se faz?" Começo a relembrar as regras para enrolar o pião assim que ele começa a me ensinar. Há toda uma técnica: primeiro se dá um nozinho no cordão e prende em uma das pontas do pião, em seguida se passa a enrolar o cordão no corpo do pião, porém, esse cordão não pode ficar sobre o outro. Se isso acontecer, precisa desenrolar novamente. Ao final, é necessário deixar uma parte do cordão sem enrolar no pião porque essa parte será enrolada em um dos dedos. Zulu, após o processo inicial de preparação do pião, contorce o corpo para um lado, estica o braço para outro lado e atira o pião na forma diagonal. "Oh, é assim", me ensina ele. Então houve várias tentativas, mas não conseguimos fazer girar o pião. Finalmente Ana chega, olha o pião com ar de autoridade e já diz de antemão: "Vich"! Esse pião não presta, ele não tem 'coisinha' para amarrar" (o pião precisava ter um relevo maior em uma das pontas para se poder amarrar o cordão). De qualquer maneira, Ana tentou algumas vezes, procedeu da mesma forma que Zulu, porém, com ainda mais segurança em seus movimentos. Depois de tentativas frustradas, disse: "Ah, Elaine, esse não dá pra brincar, olha aqui oh, isso não dá!" (aponta para aquela extremidade a que me referi acima). Combinamos então que procuraríamos outro melhor. Resolvemos brincar no parque com bola (Diário de campo, 26 jun. 2011).
\end{abstract}

Em outra brincadeira, o menino precisou ter muita paciência comigo até eu conseguir me aproximar da agilidade dele em lançar pedrinhas com um bambu oco. Com um pedaço de bambu ou cano e um pedaço de borracha, ele colocava pedrinhas dentro e as atirava. O segredo era segurar as pedrinhas na borracha e esticá-la ao máximo até que pudessem ser atiradas. No entanto, se puxasse demais, a borracha se deslocava do bambu.

É interessante perceber o sentido lúdico que as crianças podem atribuir a um pedaço de cano, a uma borracha rasgada, a alguns cacos de telhas, a um galho seco de árvore. Brougère escreve: A brincadeira é uma mutação do sentido, da realidade: as coisas aí tornam-se outras. É um espaço à margem da vida comum, que obedece às regras criadas pelas circunstâncias. Os objetos, no caso, podem ser diferentes daquilo que aparentam (BROUGÈRE, 2002,p. 99-100).

De fato, pude verificar, em várias situações, essa mutação de sentido no que diz respeito às brincadeiras com os materiais citados. Ao final das brincadeiras eram descartados, mas com a possiblidade de serem reaproveitados em outros dias enovamente significados de acordo com os desejos do momento. E não só isso; as crianças sabem muito bem aproveitar o que é descartado pelos adultos, por eles considerado inútil, e o transformar em algo valioso para elas, mesmo que por alguns instantes. 
Recorro aqui a Walter Benjamim, quando afirma que as crianças utilizam o que é abandonado pelos adultos e têm a capacidade de "fazer história com o lixo da história" (BENJAMIN, 2002). Em sua opinião, o fato de um brinquedo ser considerado atraente não significa, necessariamente, condição para uma boa brincadeira.

As experiências brincantes vividas pelas crianças nos quilombos não são apenas sinônimo de atividade, de experimento ou método, uma vez que os acontecimentos por elas construídos ou descobertos não têm caráter fugaz, mas se constituem de um fluxo de significados interligados e permanentes, pois, mesmo a subjetividade de cada uma delas, é consequência dos intercâmbios entre elas. Juntas, as crianças vão compondo o lugar e as situações, especialmente de brincadeiras, que lhes permitem ver, sentir, escutar, enfim, viver sem interrupção. Como nos fala a música de Luiz Gonzaga "Estrada de Canindé":

Quem é pobre anda a pé.

Mas o pobre vê nas estradas

o orvalho beijando a flor

Vê de perto o galo campina

que quando canta muda de cor.

Vai molhando os pés no riacho

que água fresca Nosso Senhor

Vai olhando coisa a grané (...)

As crianças da comunidade quilombola ensinam que a aprendizagem e o conhecimento não se reduzem à oralidade 'científica', prática recorrente em uma sala de aula, mas ocorrem também por meio da corporalidade ${ }^{11}$.

Também considero que a linguagem corporal não pode ficar de fora de todas as outras dimensões da infância. Aliás, muitas outras dimensões e linguagens, fundamentais para o desenvolvimento da criança, Ihes são furtadas desde muito cedo em várias culturas. A propósito e oportunamente, não é demais recordar o belo poema escrito por Loris Malaguzzi, o das "Cem linguagens da criança", do qual destaco o excerto a seguir:

A criança é feita de cem.

A criança tem cem linguagens.

Mas roubaram-lhe noventa e nove.

A escola e a cultura

Ihe separaram a cabeça do corpo [...].

Dizem-lhe: que as cem não existem.

A criança diz: ao contrário, as cem existem.

Com base em minhas observações, pareceu-me que as crianças, ao extrapolar o espaço social formal e a propalada 'domesticação dos corpos', que costuma ocorrer em tais espaços, experimentam maior autonomia e independência ${ }^{12}$, indispensáveis, em meu entender, para aprender e para ensinar. 


\section{Ensaiando um final para algo que certamente se deve reiniciar}

O sentido de tempo e, acrescento, o de lugar que as crianças constroem no quilombo onde moram parece evidenciar, ainda, um terceiro aspecto, o da ambiguidade, ou seja, o da existência de um entremeio não incluso 'nisto ou naquilo', 'filho ou aluno', 'transgressão ou passividade'. É uma procura difícil. Ao tentar interpretá-la, parece também difícil encontrar uma saída. Mas será que as ambiguidades que se apresentam serão desfeitas se encontrarmos uma terceira alternativa?

Afirmo que a vida das crianças quilombolas é também afetada por uma estrutura social, regional e local, cujo padrão de desenvolvimento busca sua conformação a macroestruturas (sociedade, economia, estrutura familiar, organização do trabalho, meios de comunicação de massa) que primam por um padrão de desenvolvimento universal e hegemônico. Portanto, não discordo do argumento de Qvortrup, de que "[...] ninguém, inclusive as crianças, pode evitar a influência de eventos mais amplos, que ocorrem além do microcosmo próximo" (2011, p. 207).

Apesar de não advogar que as crianças constroem um mundo à parte, posso pelo menos afirmar que elas fazem diferentes interpretações da realidade, porque as infâncias se constituem apoiadas por um contexto espacial, social, cultural, geográfico e relacional determinado, abrindo-se, assim, à possibilidade de perceber que, em alguma medida, elas conseguem criar brechas que não as subordinam totalmente aos constrangimentos dessa estrutura, mesmo que as macrodeterminações se imponham por sua força. Tenho consciência dos diferentes obstáculos que as crianças enfrentam no mundo e na vida social. Compreendi, porém, durante minha estada em campo, que é preciso superá-los, a começar por algumas ideias preconcebidas sobre as crianças, tais como "[...] a idéia de vítima, a idéia do senso comum que não reage, que não inventa, que não cria" (SILVA, 2003, p. 61). Não se podem excluir as possibilidades alternativas, pois, se não fossem possíveis, não haveria mudanças nem diferenças. A possibilidade de ultrapassar a fronteira da normalidade e da conformação é, a meu ver, o que permite a presença do novo.

A produção da cultura, em especial a infantil, nesse grupo de crianças, se dá em diferentes momentos, independentemente de sua relação com os adultos. Digo isso porque as crianças passam boa parte do seu cotidiano no interior da comunidade interagindo com seus pares, experimentando processos de socialização com os quais criam novos sistemas simbólicos ao estabelecer uma rede de solidariedade e corresponsabilidade com o outro, com o outro criança. Pude perceber, no decorrer da pesquisa, que esses momentos de criação ocorrem quando as crianças estão apenas entre seus pares. Mesmo ocupando um espaço de inclusão no cotidiano dos adultos, há momentos em que as crianças agem ao largo da relação mais direta que estabelecem com os adultos, ou seja, há momentos muito específicos que elas partilham apenas com seus pares. 
Concluo afirmando que algumas regularidades nas formas de ser criança na comunidade quilombola não se enquadram nas de outros contextos. Penso que isso seja importante para compreender diferentes processos de constituição da infância, desatrelando-os de um padrão normatizado. Aqui também faço uma ressalva ao destacar as especificidades das crianças moradoras dos quilombos pesquisados. $\mathrm{O}$ que as torna singulares, foi o que percebi, são as maneiras como elas se relacionam, pensam, idealizam e agem nesses espaços. Não significa, portanto, determinar, definir, impor uma infância à margem das demais, vividas por outras crianças em contextos diversos, como se os quilombolas fossem extraterrestres. É preciso não correr o risco, "do culto e do utopismo [...], na busca de um ser humano diferente e, uma vez mais, é preciso pensar a relação entre as diversas teorias que produzimos e a realidade concreta desses pequenos sujeitos que são, a um só tempo, um outro e um mesmo" (GUSMÃO, 1999, p. 50).

Penso haver aspectos comuns entre todas as crianças. Assim, as semelhanças precisam ser admitidas e avivadas, ainda que optemos por abordar e compreender determinadas dimensões do cotidiano dessas infâncias próprias de determinado grupo social ${ }^{13}$. Isto vale, em especial, para este trabalho, que trata das infâncias de uma determinada comunidade quilombola. A estada junto a elas permitiu-me testemunhar como se portam fora do "papel social" que, na hipótese de se tomar por referência nossa realidade, seria predeterminado ${ }^{14}$.

Parto da premissa de que a infância é um conceito variável no tempo e no espaço cotidianos. Minha referência é a infância quilombola aqui tratada, e descrita como um acontecer constante e diário. Elas são sim alunas, filhas e, como tais, reproduzem muito o que delas esperamos em sua comunidade; mas também são elas mesmas, reinventando sua 'rotina' e criando novos ritmos para seu dia a dia.

Entendo ser necessário começar por admitir nosso grande "desconhecimento" sobre as crianças quilombolas e abraçar a hipótese de que toda tentativa de enquadrálas num padrão, em referências fixas e unidirecionais, não faz o menor sentido se a elas aplicado. Devemos admitir nosso "desconhecimento" de sua capacidade criativa, o que não apenas nos surpreende, como impede nossa possibilidade de enxergar outras formas de pensar sobre os mundos infantis e sobre as infâncias. Assumindo, portanto, minhas incertezas, posiciono-me na perspectiva de diálogo aberto com as realidades vividas pelas crianças, na tentativa de evitar aprisioná-las em modelos engessados.

\section{Referências}

ARROYO, M.; SILVA, M. R. da. Corpo e Infância: exercícios tensos de ser criança; por outras pedagogias dos corpos. Rio de Janeiro: Vozes, 2012.

AUGE, M. Não-Lugares: introdução a uma antropologia da supermodernidade. Campinas: Papirus, 1994. 
BENJAMIN, W. Reflexões sobre a criança, o brinquedo e a educação. São Paulo: Editora 34, 2002. BROUGÉRE, G. Brinquedo e cultura. São Paulo: Cortez, 2001.

CAVALLEIRO, E. Do silêncio do lar ao silêncio escolar: racismo, preconceito e discriminação na educação infantil. São Paulo: contexto, 2007.

CORSARO, W. A reprodução interpretativa no brincar no 'faz-de-conta' das crianças. Caderno de Pesquisa, São Paulo, n.11, 2002.

EDWARDS, C. As cem linguagens da criança: a abordagem de Reggio Emilia na educação da primeira infância. Porto Alegre, Artmed Editora, 1999.

FARIA, A. L. G. O espaço físico como um dos elementos fundamentais para uma pedagogia da educação infantil. In: ; PALHARES, M. S. Educação Infantil Pós-LDB: rumos e desafios. Campinas: Autores Associados, 2003.

GARCIA, R. L. Crianças, essas conhecidas tão desconhecidas. Rio de Janeiro: DP\&A, 2002.

GUSMÃO, N. M. M. Linguagem, Cultura e Alteridade: imagens do outro. Cadernos de Pesquisa, $\mathrm{n}$. 107, jul. 1999.

LARROSA, J.; LARA, N. P. Imagens do outro. Rio de Janeiro: Vozes, 1998.

LEITE, I. B. Os quilombos no Brasil: questões conceituais e normativas. Revista Etnográfica, v. IV (2), 2000. Núcleo de Estudos sobre Identidade e Relações Interétnicas. Universidade Federal de Santa Catarina.

Humanidades insurgentes: conflitos e criminalização dos quilombos. In: RIFIOTIS, T.; RODRIGUES, T. (Orgs.). Educação em Direitos Humanos: discursos críticos e temas contemporâneos. Florianópolis: UFSC, 2008.

KRAMER, S. Infância, cultura contemporânea e educação contra a barbárie. In: BAZÍLIO, L. C.; KRAMER, S. Infância, Educação e Direitos Humanos. São Paulo: Cortez, 2003.

MOURA, C. Quilombos: resistência e escravismo. São Paulo: Ática, 1993.

O'DWYER, E. C. (Org.). Identidade Étnica e Territorialidade. Rio de Janeiro: Editora FGV, 2002.

PAIXÃO, J. P. M. Desenvolvimento humano e relações raciais. Rio de Janeiro: DP\&A, 2003.

PAULA, E. de. "VEM BRINCAR NA RUA!” Entre o Quilombo e a Educação Infantil: capturando expressões, experiências e conflitos de crianças quilombolas no entremeio desses contextos. 2014. Tese (Doutorado) - Centro de Ciências da Educação, Universidade Federal de Santa Catarina (UFSC), Florianópolis, 2014.

PINTO, M.; SARMENTO, M. J. As crianças e a infância: definindo conceitos, delimitando o campo. Texto Mimeo. Universidade do Minho - Portugal, 1997.

QVORTRUP, J. A tentação da diversidade e seus riscos. Educação e Sociedade, v. 31, out./dez. 2011.

SARMENTO, M. J. Gerações e alteridade: interrogações a partir da sociologia da infância. In: Educação \& Sociedade. Revista de Ciência da Educação. Sociologia da Infância: pesquisas com Crianças. v. 26 mai./ago. 2005. 
SAYÃO, D. T. Cabeças e Corpos, Adultos e Crianças: cadê o movimento que separou tudo isso? Revista Eletrônica de Educação, v. 2, n. 2, nov. 2008. Artigos. ISSN 1982-7199. Programa de Pós-Graduação em Educação.

SILVA, M. R. Trama doce-amarga: (exploração do) trabalho infantil e cultura lúdica. Ijuí: Ed. Unijuí; São Paulo: Hucitec, 2003.

Corpo e Infância: exercícios tensos de ser criança; por outras pedagogias dos corpos. Rio de Janeiro: Vozes, 2012.

Artigo recebido em: 29/05/2019

Aprovado em: 01/08/2019

\section{Contato para correspondência:}

Elaine de Paula. E-mail: naniidepaula@hotmail.com

1 Frase expressa por 'Alice', cinco anos, ao ser indagada sobre o que significava quilombo para ela.

2 Tese de doutorado defendida em 2014 (PAULA, 2014). Referência, ao final deste texto.

3 Os quilombos em que a pesquisa foi realizada estão situados em Garopaba- Santa Catarina: Quilombo Morro do Fortunato e Quilombo Aldeia.

4 Contemplo na pesquisa de doutorado o histórico dos quilombos a partir de diferentes perspectivas e autores.

5 Os organismos internacionais, entre os quais a ONU e a Unicef, têm levantado, reiteradamente, esses dados sobre o Brasil. De acordo com Miguel Arroyo (2012), vinte milhões de crianças e adolescentes no Brasil vivem abaixo da linha da pobreza.

6 Não sou ingênua e, neste caso, tampouco romântica; compreendi, principalmente após minha incursão nos campos de pesquisa, que as crianças quilombolas vivenciam certa precariedade de condições materiais de subsistência nas comunidades em que vivem. Da mesma forma que nas instituições de educação infantil, experienciam violência simbólica, e se dão conta, mesmo que muitas vezes camuflada pelo discurso da igualdade. Há algumas pesquisas que levantam dados como os que constatei em campo: Paixão (2003); Cavalleiro (2000).

7 Maculelê: dança de origem afro-indígena, realizada em momentos festivos em um dos quilombos pesquisados. Já o Samba de Roda ocorre sempre que os grupos se reúnem no segundo quilombo em que estive presente, seja em dias de festa, seja em almoços nos domingos. Quanto à Capoeira, de acordo com Amélia Conrado (2006), da Universidade Federal da Bahia, essa forma de expressão é também considerada dança, um conjunto de expressões da arte corporal de herança africana.

8 Simbolização entendida como construção de sentidos ou de interpretações por meio das relações estabelecidas entre pares e das mediações entre as crianças e tudo aquilo que elas têm à disposição, seja material, seja da imaginação. 
9 Desenvolvo melhor esta ideia na tese de doutorado.

10 Não trago, neste texto, como também o fiz na tese de doutorado, o nome real das crianças, mas o nome que elas próprias escolheram por meio de uma dinâmica com elas desenvolvida durante a pesquisa empírica

11 Este conceito pode ser lido em Débora Sayão (2008).

12 Insisto em ressaltar que, ao me referir às crianças como autônomas e independentes, não nego sua interdependência (assim como os adultos) com o outro, seja o outro criança, adulto ou o mundo físico e natural.

13 Não aprofundo este aspecto neste espaço, mas penso ser importante a leitura do texto de Jens Qvortrup (2010): A Tentação da Diversidade - e seus riscos. In: Educ. Soc. Campinas, v. 31, n. 113, out./dez. 2010. p. 1.121-1.136.

14 Fiz referência, e delas tratei na Tese de Doutorado, a algumas evidências aos modos de ação das crianças nas escolas como 'fora do lugar social reservado a elas'. 